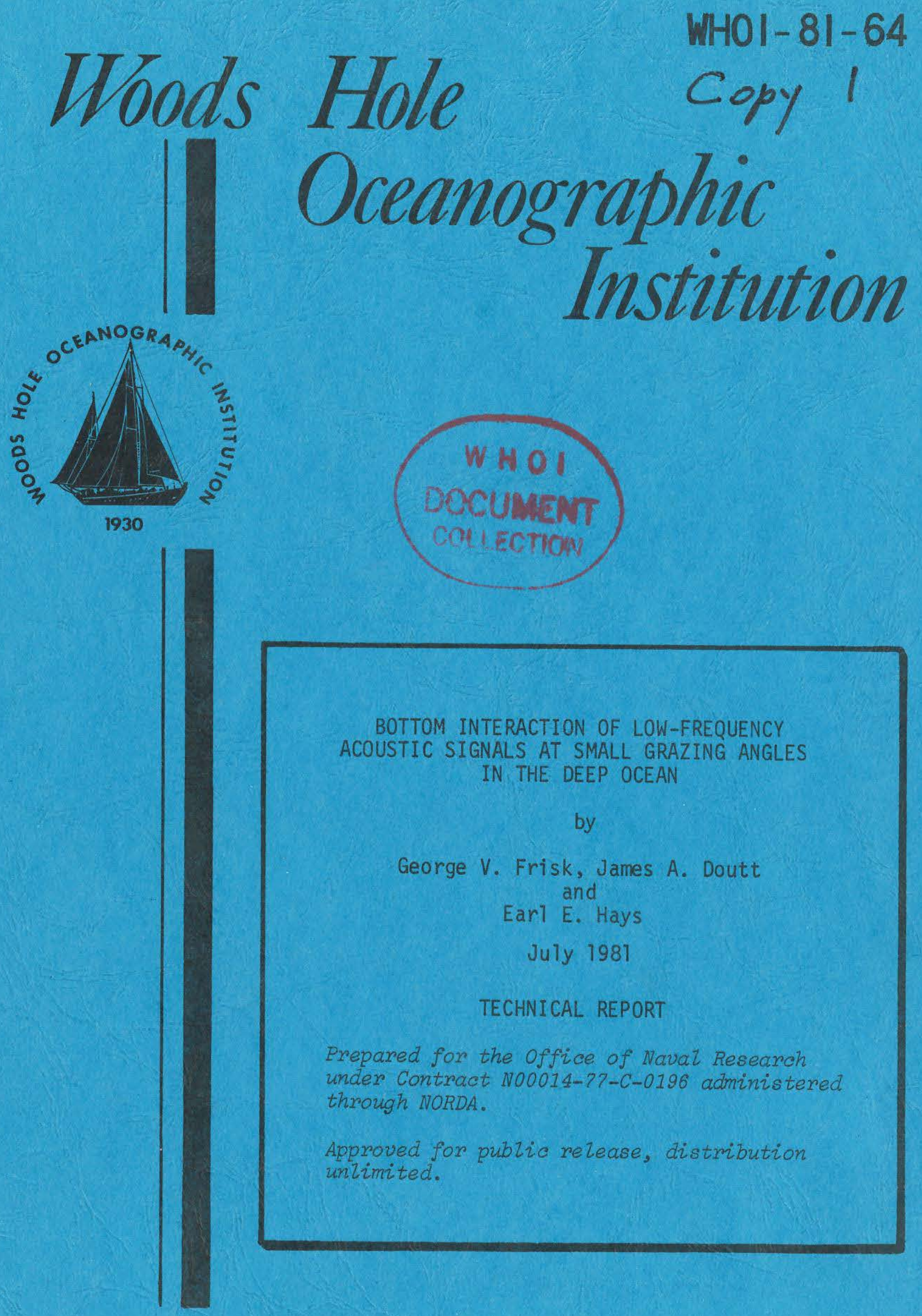

WOODS HOLE, MASSACHUSETTS 02543 
WHOI $-81-64$

\author{
BOTTOM INTERACTION OF LOW-FREQUENCY \\ ACOUSTIC SIGNALS AT SMALL GRAZING ANGLES \\ IN THE DEEP OCEAN
}

\author{
by \\ George V. Frisk, James A. Doutt \\ and \\ Earl E. Hays \\ WOODS HOLE OCEANOGRAPHIC INSTITUTION \\ Woods Hole, Massachusetts 02543 \\ July 1981
}

TECHNICAL REPORT

Prepared for the Office of Naval Research under Contract N00014-77-C-0196 administered through NORDA.

Reproduction in whole or in part is permitted for any purpose of the United States Government. In citing this report in a bibliography, the reference given should be to: J. Acoust. Soc. Am. 69(1): 84-94 (Jonuary 1981).

Approved for public release; distribution unlimited.

Approved for Distribution: Earl E. Hays, Chairman Department of Ocean Engineering 


\title{
Bottom interaction of low-frequency acoustic signals at small grazing angles in the deep ocean
}

\author{
George V. Frisk, James A. Doutt, and Earl E. Hays \\ Woods Hole Oceanographic Institution, Woods Hole, Massachusetts 02543 \\ (Received 4 July 1980; accepted for publication 15 September 1980) \\ The results of a deep-ocean bottom interaction experiment are presented in which the effects of both bottom \\ refraction and subbottom reflection were observed. Data were obtained in the Hatteras Abyssal Plain using a \\ deep towed $220-\mathrm{Hz}$ pulsed $\mathrm{cw}$ source and two receivers anchored near the bottom. For ranges between 1 and \\ $6 \mathrm{~km}$, corresponding to bottom grazing angles less than $13^{\circ}$, the quadrature components of the received \\ signals were recorded digitally. The observed amplitude shows a strong spatial interference pattern which is \\ composed of the direct and bottom interacting arrivals. It is shown that for small source-receiver separations, \\ the bottom return is dominated by a strong subbottom reflection. With increasing separation, this arrival \\ evolves into a refracted arrival due to the presence of a positive sound-speed gradient in the sediment \\ overlying the subbottom. Because of the gradient, a caustic is formed, and corresponding high intensity \\ regions are observed in the data at the expected ranges. Values of sediment layer thickness, sound-speed \\ gradient, and sound-speed drop at the water-bottom interface are obtained from best fits to the data using ray \\ theory, normal mode theory, and the parabolic equation method. These values are consistent with those \\ obtained in nearby locations by other workers. The success of the parabolic equation method indicates that at \\ small grazing angles, the bottom interaction process may be modeled as a propagation process combined with \\ the effect of a perfect, soft subbottom reflector. A value of sediment attenuation, $0.0015 \mathrm{~dB} / \mathrm{m}$ at $220 \mathrm{~Hz}$, is \\ also inferred from the data and is among the lowest values reported to date in the literature.
}

PACS numbers: 43.30.Gv, 43.30.Bp, 43.30.Dr, 92.10.Vz

\section{INTRODUCTION}

The subject of low-frequency acoustic refraction through deep-sea sediments with positive sound-speed gradients has an extensive literature. In addition to reviewing the earlier work in this area, Christensen et al., ${ }^{1}$ have studied this problem using explosive source data. They show that for frequencies less than $200 \mathrm{~Hz}$, bottom grazing angles less than $25^{\circ}$, and a sediment layer at least a few hundred feet thick, a significant amount of acoustic energy can be transmitted between source and receiver in the water column via shallow refracted paths in the sediment. Also using explosives, Dicus ${ }^{2}$ demonstrates the importance of the refracted arrival for grazing angles less than $30^{\circ}$ and frequencies between 40 and $90 \mathrm{~Hz}$. He further observes the $\pi / 2$ phase shift associated with the caustic ${ }^{3-6}$ which is formed due to the presence of a positive sound speed gradient. Hanna ${ }^{7}$ shows that it is necessary to include a sediment-refracted path in order to explain the interference pattern in his observed transmission loss data for a $95-\mathrm{Hz} \mathrm{cw}$ source.

For thinner sediment layers and/or steeper grazing angles, subbottom reflections may play a significant role in the bottom interaction process. For example, Brown and Ricard ${ }^{8}$ show that the observed interference pattern in their $120.5-\mathrm{Hz}$ pulsed $\mathrm{cw}$ data at grazing angles greater than $44^{\circ}$ can be explained by including the reflection from a subbottom $130 \mathrm{ft}$ below the waterbottom interface. In their model, this layer is assumed to have a constant sound speed.

The purpose of this paper is to present the results of a deep-ocean bottom interaction experiment in which the effects of both bottom refraction and subbottom reflection were observed. In Sec. I, we present a des- cription of the experiment and data analysis. In Sec. II, we present a ray theoretical interpretation of the data which demonstrates that the observed amplitude is dominated by the effects of a strong subbottom reflector and a positive sound-speed gradient in the overlying sediment. We also infer values of sediment layer thickness, sound-speed gradient, sound-speed drop at the waterbottom interface, and sediment attenuation from best fits to the data using ray theory, normal mode theory, and the parabolic equation method.

\section{EXPERIMENTAL DESCRIPTION AND ANALYSIS}

The experiment was performed in September 1978 in the Hatteras Abyssal Plain at $34^{\circ} \mathrm{N}, 67^{\circ} \mathrm{W}$ in $5150 \mathrm{~m}$ of water. The experimental configuration is shown in Fig. 1. A $220-\mathrm{Hz}$ battery powered source ${ }^{9}$ with an acoustic power output of $177 \mathrm{~dB}$ re $1 \mu \mathrm{Pa}$ at $1 \mathrm{~m}$ was suspended on the trawl wire of $\mathrm{R} / \mathrm{V}$ OCEANUS. The source emitted a 4-s pulse every $14 \mathrm{~s}$ which was accompanied by a 7ms $11-\mathrm{kHz}$ pulse transmitted si multaneously by a pinger mounted on the source. The receiving system consisted of two DIBOS ${ }^{9}$ receivers moored on the bottom, with one hydrophone $2.7 \mathrm{~m}$ and the other $51.4 \mathrm{~m}$ above the bottom. The DIBOS (Digital Buoy System) is a microprocessor controlled quadrature demodulator, digitizer, and recorder as shown in Fig. 2. Upon reception of the $11-\mathrm{kHz}$ pulse, the DIBOS entered a data acquisition mode. The incoming low-frequency signal was bandpass filtered and bandshifted to base band $(0 \mathrm{~Hz})$ through coherent quadrature phase demodulators. The quadrature components were then filtered with a $2-\mathrm{Hz}$ filter and digitized at a $5-\mathrm{Hz}$ rate using a 12-bit analogto-digital converter. The arrival time (to tenths of $\mathrm{ms}$ ) of the $11-\mathrm{kHz}$ pulse and $8 \mathrm{~s}$ of $220-\mathrm{Hz}$ data (corresponding to 40 samples of each quadrature component) were 


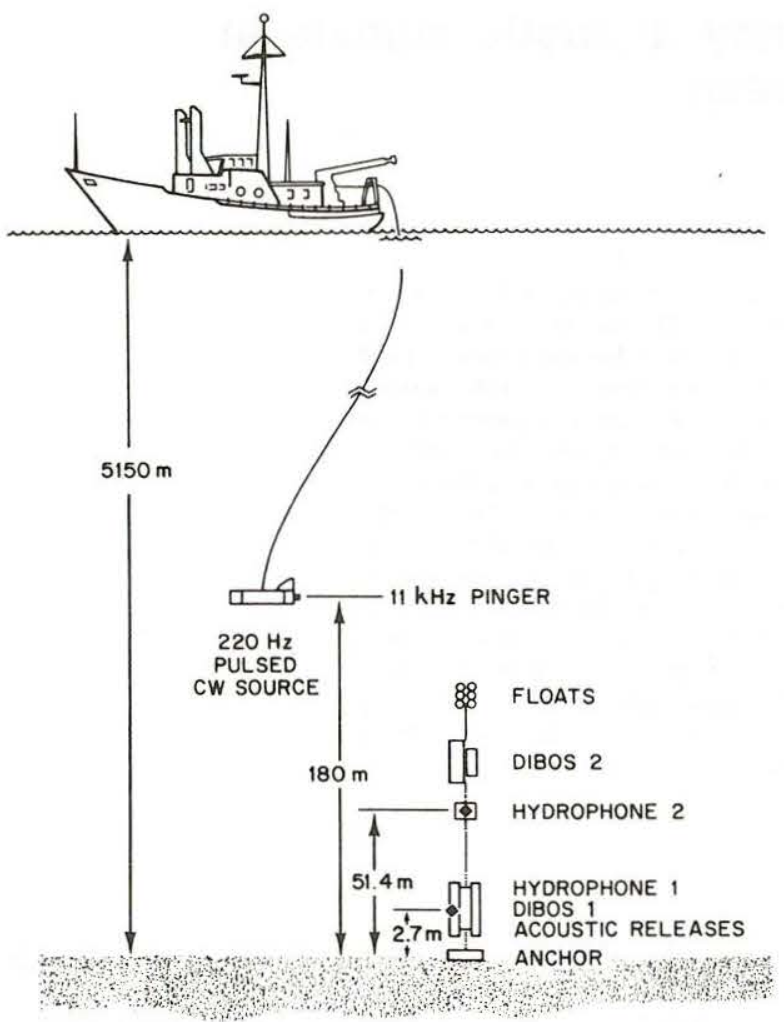

FIG. 1. Experimental configuration.

then recorded on cassette tape. This sequence was repeated as the ship drifted away from the receiver mooring at a speed of about $\frac{1}{2} \mathrm{kn}$. With a $220-\mathrm{Hz}$ signal and 14-s duty cycle, this corresponded to a ping occurring at approximately every $\frac{1}{2}$ wavelength in range. The clocks in the source and receivers were synchronized and have a stability of about one part in $10^{9}$ per day. The $11-\mathrm{kHz}$ emission time at the source and arrival time at the receivers could then be used to determine horizontal range between source and receivers. The arrival times of the direct and bottom reflected $11-\mathrm{kHz}$ pulses received on the ship's depth recorder were used to determine the source height above the bottom. It

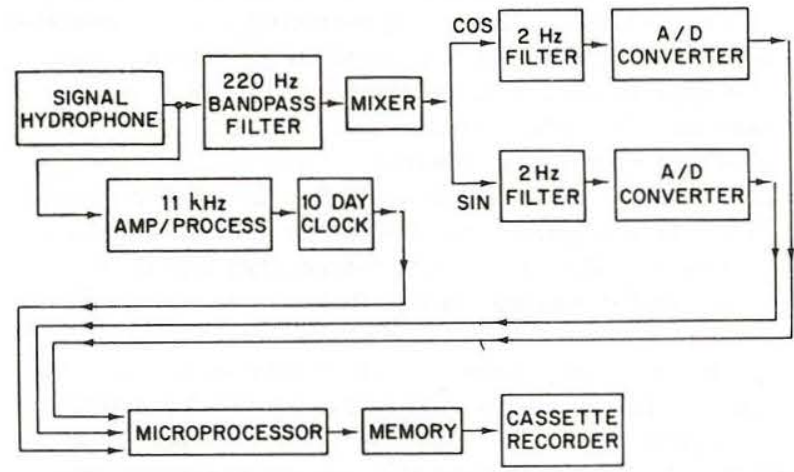

FIG. 2. DIBOS block diagram. varied almost monotonically from $155 \mathrm{~m}$ at the beginning to $205 \mathrm{~m}$ at the end of the experiment. An average source height of $180 \mathrm{~m}$ was used in all of our calculations.

A schematic diagram of the data analysis procedure is shown in Fig. 3. Here, $A_{i} \cos \phi_{i}$ and $A_{i} \sin \phi_{i}$ are the sampled quadrature components, with $A_{i}$ the amplitude and $\phi_{i}$ the phase. By examining many 8 -s records of the received signal for stability, it was determined that the signal was in a steady-state condition in the 4th s. The five samples of each quadrature component in that second were then averaged to obtain an estimate of the signal amplitude $\hat{A}$ and phase $\hat{\phi}$ at range $r$. The amplitude was then smoothed by using a four-point running average in range, and the relative amplitude in $\mathrm{dB}$ was computed. The results of this analysis for the two receivers are shown in Fig. 4.

\section{DATA INTERPRETATION AND COMPARISON WITH THEORY}

We shall interpret the experimental results in Fig. 4 as measurements of the spatial part of the steady-state acoustic field at $220 \mathrm{~Hz}$. The DIBOS removes the temporal variation at the carrier frequency, while looking only in the 4th s satisfies the steady-state requirement. For a source speed of $\frac{1}{2} \mathrm{kn}$ and frequency of $220 \mathrm{~Hz}$, the Doppler shift is $0.036 \mathrm{~Hz}$; Doppler effects are therefore assumed to be small and are neglected. Because of the near-bottom geometry and 14-s duty cycle, we also assume that the effects of surface reflection and water multiples are negligible. However, because of the proximity to the bottom, the total field contains the direct arrival in addition to the bottom interacting portion. Finally, we assume that the water and bottom are horizontally stratified.

Although our discussion will focus upon the behavior of the measured amplitude, we will first make one comment about the phase. A striking feature of the phase is its rapid variation with range. If we had only a direct spherical wave in an isovelocity ocean at long ranges (»source/receiver heights), then the phase would go through a $2 \pi$ excursion whenever the range changed by a wavelength $(\approx 7 \mathrm{~m}$ at $220 \mathrm{~Hz})$. This behavior is roughly what we see in the data, although it is complicated considerably by the bottom return.

In order to compare the measured amplitude with theoretical predictions, we must first determine a suitable set of acoustic parameters for the bottom. The results of seismic reflection and refraction profiling ${ }^{10,11}$ within $60 \mathrm{NM}$ of our site are presented in Fig. 5. From Houtz and Ewing ${ }^{10}$ we also infer that the top sediment layer may have a positive sound-speed gradient of about 1-2 $\mathrm{s}^{-1}$ and a drop relative to the water sound speed of about $1 \%-2 \%$ at the water-bottom interface. Our model calculations showed, however, that this information was not sufficiently detailed to obtain a successful comparison with the experimental data. The calculated acoustic field was far too sensitive to the values of the input parameters that were used. We therefore used the archival data as a starting point and varied the bottom 


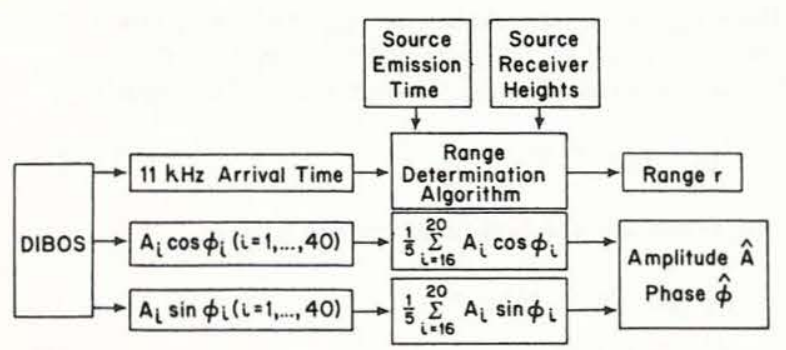

FIG. 3. Schematic diagram of data analysis procedure.

parameters until we obtained best fits to the data. The results of this approach using ray theory, normal mode theory, and the parabolic equation method are presented below. In our discussion, we will concentrate on the amplitude behavior between 1000 and $4000 \mathrm{~m}$, which is the region of greatest variability and highest signal-tonoise ratio in the data. In order to aid in our understanding of the results, we shall first present a ray theoretical interpretation of the data.

\section{A. A ray theoretical interpretation of the data}

Although ray theory is the least successful in providing detailed agreement with the data, it is the most helpful in terms of illuminating the physics of the bottom interaction process. First, let us examine the gross features of the amplitude data in Fig. 4. Region $A$ is characterized by a dense interference pattern; region $\mathrm{B}$ is an area of high intensity which is especially evident for the $2.7-\mathrm{m}$ receiver; region $\mathrm{C}$ exhibits a much broader interference pattern than that found in region $\mathrm{A}$. This behavior can be understood by studying the ray diagram in Fig. 6, which shows the principal types of ray paths that dominate the interaction in this case. The sound-speed profile used is shown in Fig. 7, though at this point we need only focus upon its gross features: A weak positive gradient in the water, a drop in sound speed at the water-bottom interface, a strong positive gradient in the top sediment layer, and a strong subbottom reflector. We postulate the following model of the bottom interaction process: For close-in ranges, the bottom return is dominated by a subbottom reflection. This when combined with the direct arrival yields the Lloyd mirror-like dense interference pattern of region $A$. With increasing range this arrival evolves into a refracted arrival due to the gradient in the overlying sediment. The gradient causes the formation of a caustic and the corresponding high intensity region in region $B$. Further out in range, the bottom return consists of a shallow refracted arrival, which when combined with the direct, yields the broad interference lobes of region $\mathrm{C}$. We shall now develop this model in detail.

Let us consider the possible ray paths which undergo a single bottom interaction. These are shown in Fig. 8. We will incorporate the effects of the water-bottom and sediment-subbottom interfaces by using the plane-wave reflection coefficients associated with these interfaces. The pressure field due to the bottom reflected path is given by

$$
p_{B}=R_{01}\left(\theta_{B}\right) A_{B} e^{i \Theta_{B}},
$$

where $A_{B}$ is the ray amplitude associated with geometrical spreading, $\Phi_{B}$ is the ray phase, $\theta_{B}$ is the ray angle at the water-bottom interface, and $R_{01}$ is the Ray-

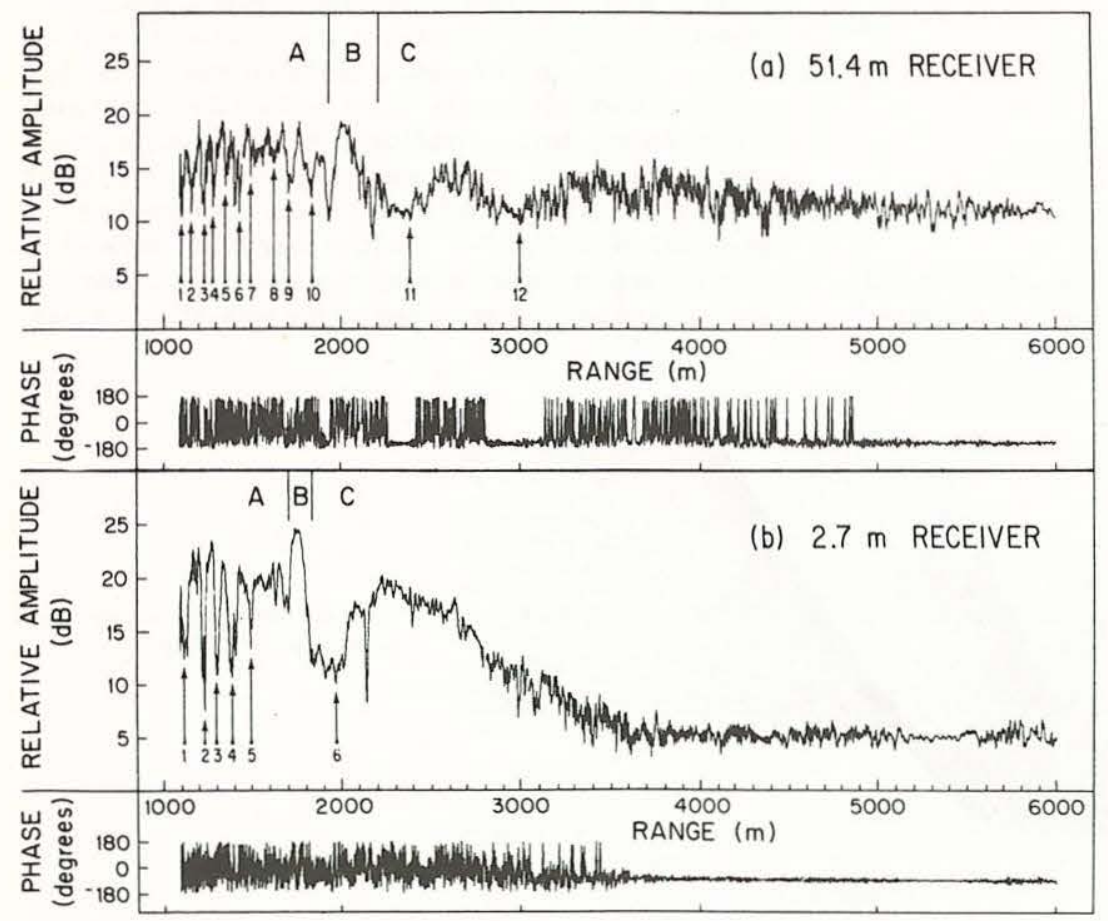

FIG. 4. Relative amplitude (dB) and phase versus range at the (a) $51.4-\mathrm{m}$ and (b) 2.7-m receivers. 
- EMERY et al

- HOUTZ \& EWING

\$ PRESENT EXPERIMEN

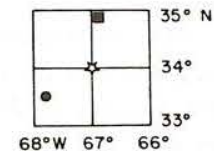

EMERY et al (1970)

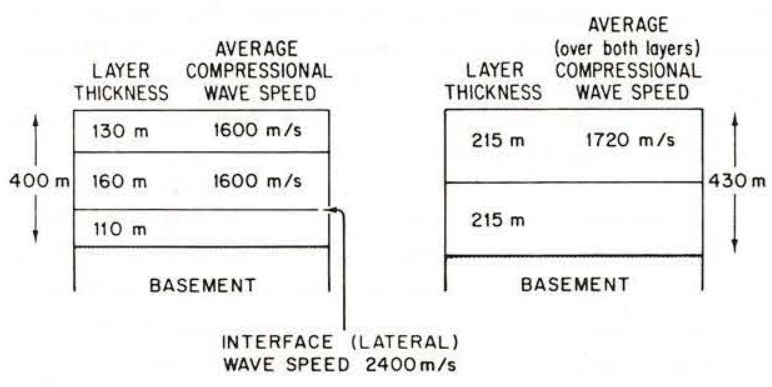

FIG. 5. Experimental sites and acoustic bottom parameters measured by other authors.

leigh reflection coefficient ${ }^{12}$ for a plane-wave incident from a half-space with sound speed $c_{0}$ onto a half-space with speed $c_{1}$. For the subbottom reflected path, we have

$$
p_{\mathrm{SB}}=T_{10} R_{23} T_{01} A_{\mathrm{SB}}^{\prime} e^{i \Phi_{\mathrm{SB}}},
$$

where $R_{23}$ is the Rayleigh reflection coefficient between two media with sound speeds $c_{2}$ and $c_{3}$, and $T_{01}\left(T_{10}\right)$ is the pressure transmission coefficient from medium $0(1)$ to $1(0)$. Using the relations ${ }^{12}$

$$
\begin{aligned}
& T_{01}=1+R_{01}, \\
& T_{10}=1+R_{10}, \\
& R_{01}=-R_{10},
\end{aligned}
$$

we obtain

$$
p_{\mathrm{SB}}=\left[1-R_{01}^{2}(\theta)\right] R_{23}\left(\theta_{\mathrm{SB}}\right) A_{\mathrm{SB}}^{\prime} e^{i \oplus_{\mathrm{SB}}},
$$

with $\theta$ the ray angle at the water-bottom interface and $\theta_{\mathrm{SB}}$ the ray angle at the sediment-subbottom interface.
Here $\Phi_{\mathrm{SB}}$ is the ray phase and $A_{\mathrm{SB}}^{\prime}$ is the amplitude which includes both a geometrical spreading factor $A_{\mathrm{SB}}$ and attenuation $\alpha^{\prime}$ along the sediment path length $L_{\mathrm{SB}}$ :

$$
A_{\mathrm{SB}}^{\prime}=A_{\mathrm{SB}} e^{-\alpha^{\prime} L \mathrm{SB}} \text {. }
$$

The result for the bottom refracted path is

$$
\begin{aligned}
& p_{R}=\left[1-R_{01}^{2}\left(\theta_{R}\right)\right] A_{R}^{\prime} e^{i \Phi_{R}}, \\
& A_{R}^{\prime}=A_{R} e^{-\alpha^{\prime} L_{R}},
\end{aligned}
$$

where $\theta_{R}$ is the ray angle at the water-bottom interface, $\Phi_{R}$ is the ray phase, $A_{R}$ is the ray amplitude due to geometrical spreading, and $L_{R}$ is the sediment path length.

In order to make computations with our ray model, we require knowledge of the appropriate acoustic parameters of the bottom. For this purpose we shall use the geoacoustic model shown in Fig. 7. It will be shown in Sec. IIB and IIC that these parameters yield the best theoretical ray and normal mode fits to the amplitude data.

The key to understanding the ray model lies in the determination of the range of angles associated with the various ray paths and the corresponding behavior of the reflection coefficients $R_{01}$ and $R_{23}$. The variation in the angles for ranges between 1000 and $4000 \mathrm{~m}$ is shown in Table I. The reflection coefficients $R_{01}$, with magnitude $\left|R_{01}\right|$ and phase $\phi_{01}$, and $R_{23}$, with magnitude $\left|R_{23}\right|$ and phase $\phi_{23}$, evaluated over the range of angles of interest are shown in Fig. 9. Sediment attenuation is incorporated by making the wavenumber $k_{1}=\omega / c_{1}$ complex. Because of the drop in sound speed at the water-bottom interface, $R_{01}$ exhibits the Brewster (intromission) angle phenomenon of total transmission. As a result, except at extreme grazing incidence, only a small amount of energy is reflected at the water-bottom interface. By the same token, a large amount of energy is transmitted across this interface into the subbottom reflected and bottom refracted paths. Upon hitting the subbottom the ray, with grazing angle less than critical, is virtually totally reflected and simply undergoes a phase shift (c.f. Fig. 9b). On the other hand, rays which enter the subbottom at steeper angles, greater than critical, are largely absorbed by the subbottom. Final-

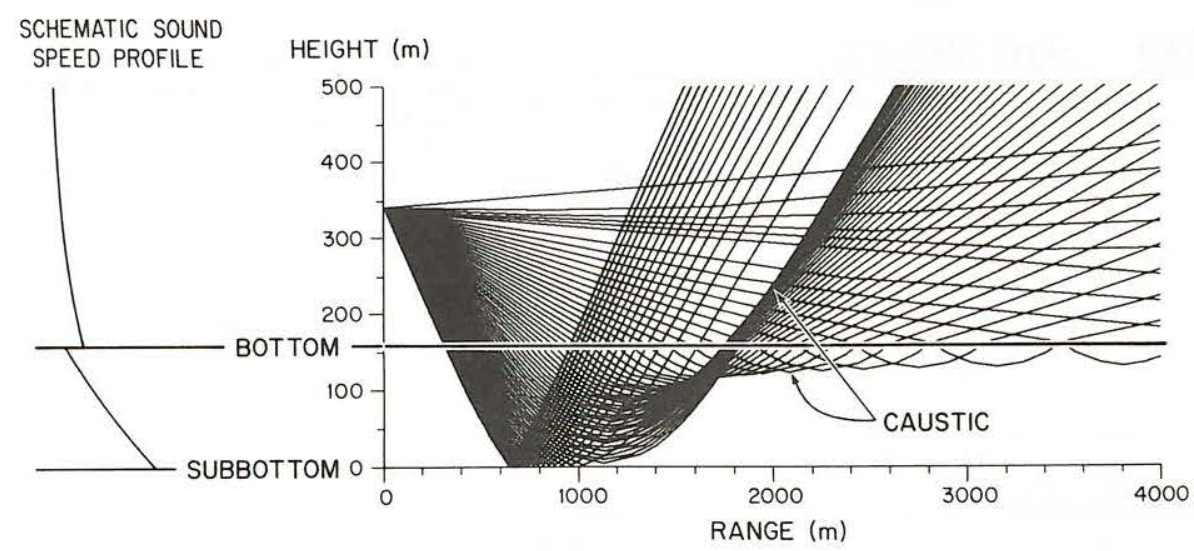

FIG. 6. Schematic sound-speed profile and ray diagram. 


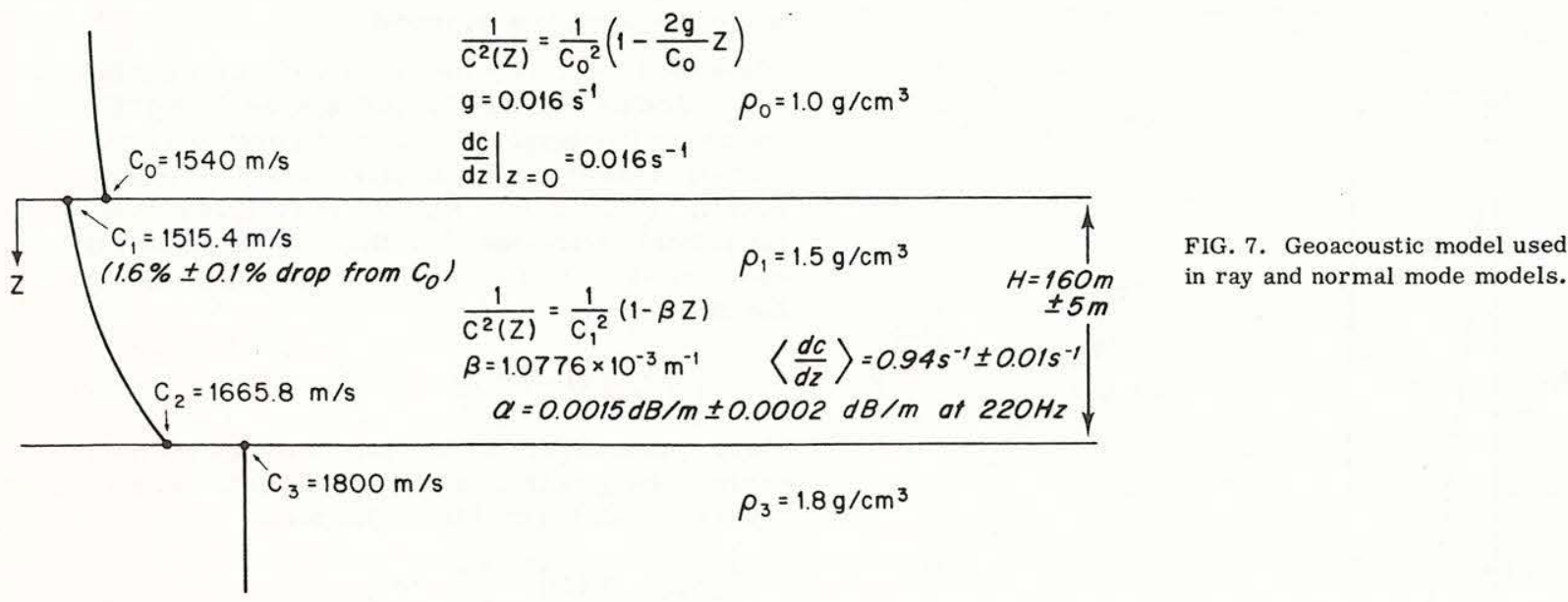

ly, again because of the behavior of $R_{01}$, the subbottom reflected and bottom refracted paths lose only a small amount of energy when they traverse the bottom-water interface and re-enter the water column.

The dominance of the subbottom reflected and bottom refracted paths over the bottom reflected path is confirmed by calculating the propagation loss along the three paths using Eqs. (1), (4), and (5). The results of this calculation and that for the direct path $\left(A_{D}\right.$ is the ray amplitude and $\Phi_{D}$ the phase)

$$
p_{D}=A_{D} e^{i \Phi_{D}}
$$

are shown in Fig. 10. We computed the geometrical spreading losses using a ray program developed at the NATO SACLANT ASW Research Centre. ${ }^{13}$ The program interpolates linear sound-speed gradients between the input profile points; the ray equations then have exact solutions within each linear gradient layer.

The three-path hypothesis (direct, subbottom reflected, and bottom refracted) is further corroborated by examining the observed interference patterns in detail. For two interfering paths with (real) amplitudes $A_{1}$ and $A_{2}$ and phases $\Phi_{1}$ and $\Phi_{2}$, the total pressure is given by

$$
p=A_{1} e^{i \Phi_{1}}+A_{2} e^{i \Phi_{2}} .
$$

In our case path 1 is the direct path with travel time $T_{1}$,

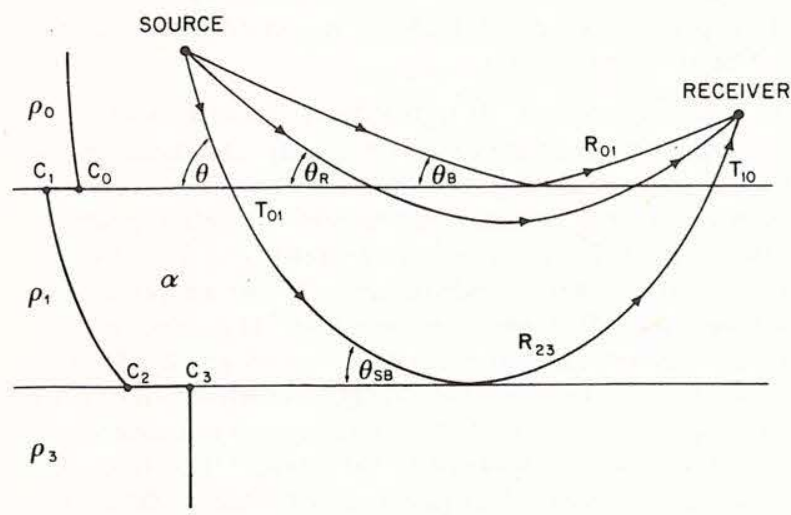

FIG. 8. Single bottom-interacting ray paths. so that

$$
\Phi_{1}=\omega T_{1} .
$$

Path 2 is either the subbottom reflected or bottom refracted path with travel time $T_{2}$, so that

$$
\Phi_{2}=\omega T_{2}+\Phi .
$$

Here $\Phi$ is an additional phase shift arising from interaction with the subbottom, in which case

$$
\Phi=\phi_{23},
$$

or interaction with the caustic,$^{3-6}$ in which case

$$
\Phi=90^{\circ} \text {. }
$$

The amplitude associated with Eq. (7) is given by

$$
|p|=\left[A_{1}^{2}+A_{2}^{2}+2 A_{1} A_{2} \cos \left(\Phi_{2}-\Phi_{1}\right)\right]^{1 / 2},
$$

and has nulls at ranges such that

$$
\Phi_{2}-\Phi_{1}=\omega\left(T_{2}-T_{1}\right)+\Phi=(2 n+1) \pi, \quad(n=0,1,2, \ldots) .
$$

The experimental null ranges as determined from Fig. 4 , and the theoretical null ranges calculated from Eq. (11) using the geoacoustic model in Fig. 7 are shown in Table II. The spacing between adjacent nulls is also tabulated. The ray travel times were computed using the La Spezia ray trace program. ${ }^{13}$ The overall agreement between theory and experiment is good. It is clear that the addition of a $90^{\circ}$ phase shift, due to the caustic, to the bottom refracted path improves the results.

TABLE I. Grazing angles of bottom-interacting ray paths for ranges between 1000 and $4000 \mathrm{~m}$ using the geoacoustic model of Fig. 7.

\begin{tabular}{ccccc}
\hline \hline & \multicolumn{2}{c}{ (a) $51.4-\mathrm{m}$} & \multicolumn{2}{c}{ (b) $2.7-\mathrm{m}$} \\
receiver & $\begin{array}{c}\text { receiver } \\
\text { Ginimum } \\
\text { value }\end{array}$ & $\begin{array}{c}\text { Maximum } \\
\text { value }\end{array}$ & $\begin{array}{c}\text { Minimum } \\
\text { value }\end{array}$ & $\begin{array}{c}\text { Maximum } \\
\text { value }\end{array}$ \\
\hline$\theta_{B}$ & $3^{\circ}$ & $13^{\circ}$ & $1^{\circ}$ & $10^{\circ}$ \\
$\theta_{R}$ & $5^{\circ}$ & $22^{\circ}$ & $5^{\circ}$ & $22^{\circ}$ \\
$\theta^{\circ}$ & $22^{\circ}$ & $31^{\circ}$ & $22^{\circ}$ & $30^{\circ}$ \\
$\theta_{\mathrm{SB}}$ & $0^{\circ}$ & $22^{\circ}$ & $0^{\circ}$ & $20^{\circ}$ \\
\hline \hline
\end{tabular}



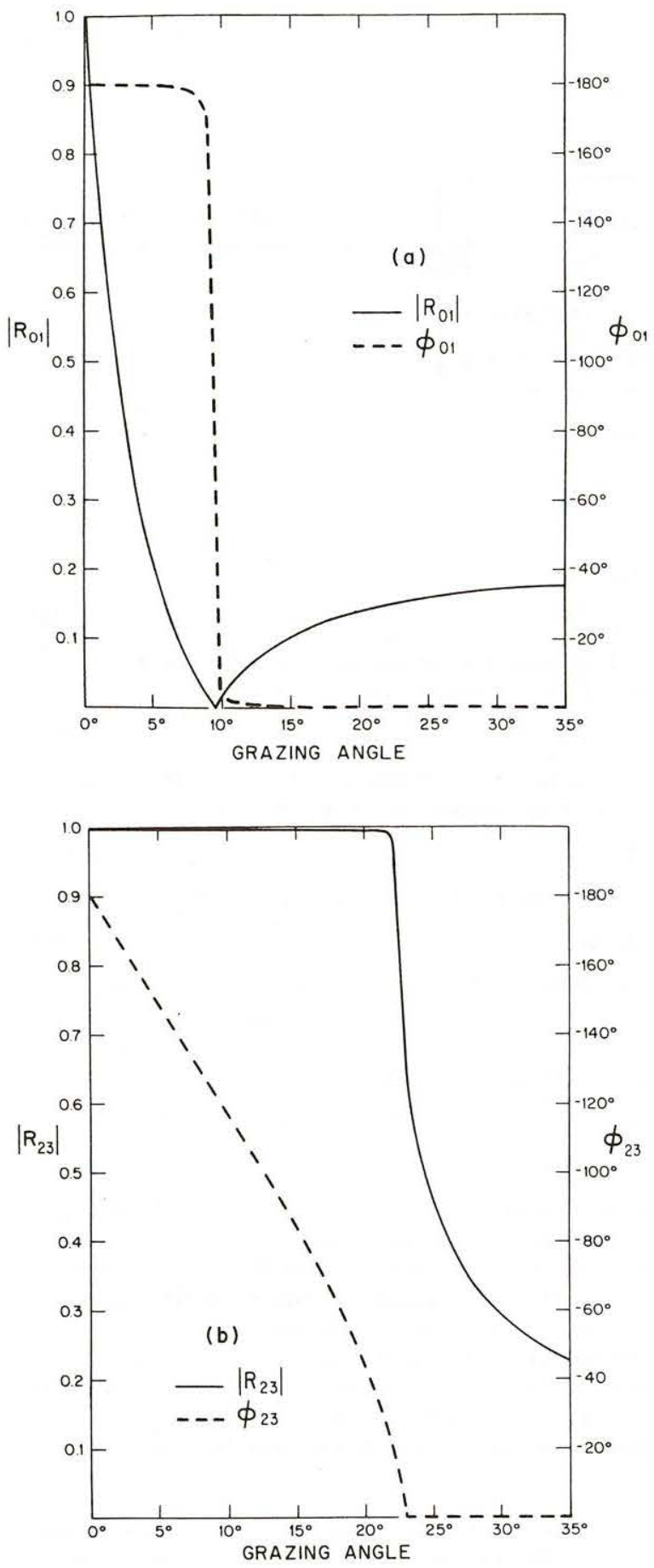

FIG. 9. Rayleigh reflection coefficients at the (a) water-bottom and (b) sediment-subbottom interfaces for the geoacoustic model of Fig. 7.

The peak-to-null difference in amplitude in the subbottom reflection portion of the interference pattern can be used to infer a value of sediment attenuation. This method is discussed in the Appendix.

\section{B. Comparison with a ray model}

In order to obtain the best ray theoretical fit to the amplitude data, we used the ray program BOTRAY developed by Bartberger. ${ }^{14}$ This model assumes a refracting ocean and sediment layer overlying an isovelocity subbottom (c.f. Fig. 7). The program uses pseudolinear sound-speed profiles, for which the ray equations have exact solutions. In the water, the profile has the form

$$
\frac{1}{c^{2}(Z)}=\frac{1}{c_{0}^{2}}\left(1-\frac{2 g}{c_{0}} Z\right), \quad Z<0,
$$

where $c_{0}$ is the speed in the water at the water-bottom interface and $g$ is the gradient. In the sediment layer of thickness $H$, the profile has the form

$$
\begin{aligned}
& \left(\frac{\omega}{c(Z)}-i \alpha^{\prime}(Z)\right)^{2}=\left(\frac{\omega}{c_{1}}-i \alpha_{1}^{\prime}\right)^{2} \\
& -\left[\left(\frac{\omega}{c_{1}}-i \alpha_{1}^{\prime}\right)^{2}-\left(\frac{\omega}{c_{2}}-i \alpha_{2}^{\prime}\right)^{2}\right] \frac{Z}{H}, \quad Z>0,
\end{aligned}
$$

where $c_{1}$ and $c_{2}$ are the speeds and $\alpha_{1}^{\prime}$ and $\alpha_{2}^{\prime}$ the attenuations at the top and bottom of the layer, respectively. In our computations we assumed $\alpha_{1}^{\prime}=\alpha_{2}^{\prime}$. We note that even in that case, the form of the profile in Eq. (12b) introduces an attenuation gradient. For small attenuations $\left(\alpha^{\prime} \ll \omega / c\right)$, however, this gradient is negligible, and the attenuation is effectively constant. Also for small $\alpha^{\prime}$, the functional form of the sound-speed profile in the sediment layer reduces to that shown in Fig. 7 . In BOTRAY, reflection at the boundaries is incorporated via plane-wave reflection coefficients. The program retains the contributions of paths, including those which are multiply reflected or refracted within the sediment layer, as long as their amplitudes do not fall more than $130 \mathrm{~dB}$ below the maximum. The ray paths are coherently summed at the receiver to obtain the total field. Our best fit to the data using BOTRAY was obtained using the geoacoustic model in Fig. 7. The theoretical results with and without the $\pi / 2$ caustic phase correction are shown superimposed upon the data in Fig. 11. As expected, the uncorrected and corrected theories yield identical results in the subbottom interference region. In the bottom refraction region, however, the phase corrected theory yields significantly improved results. The disagreement between theory and experiment in the amplitude in the vicinity of the caustic is not surprising, since BOTRAY does not contain a caustic amplitude correction.

In obtaining the best fit to the data, it was found that the predicted amplitude was most sensitive to variations in the sound-speed drop at the water-bottom interface, the sediment layer thickness, and the gradient and attenuation in the layer. The error values indicated in Fig. 7 are the amounts by which it was necessary to change a given parameter, with all others being held fixed, to produce a clearly discernible change in the predicted amplitude results. The amplitude was relatively insensitive to the acoustic properties of the subbottom as long as they caused the subbottom interacting ray paths to be critically reflected. For example, a subbottom sound-speed value of $5000 \mathrm{~m} / \mathrm{s}$ yielded amplitude curves almost indistinguishable 

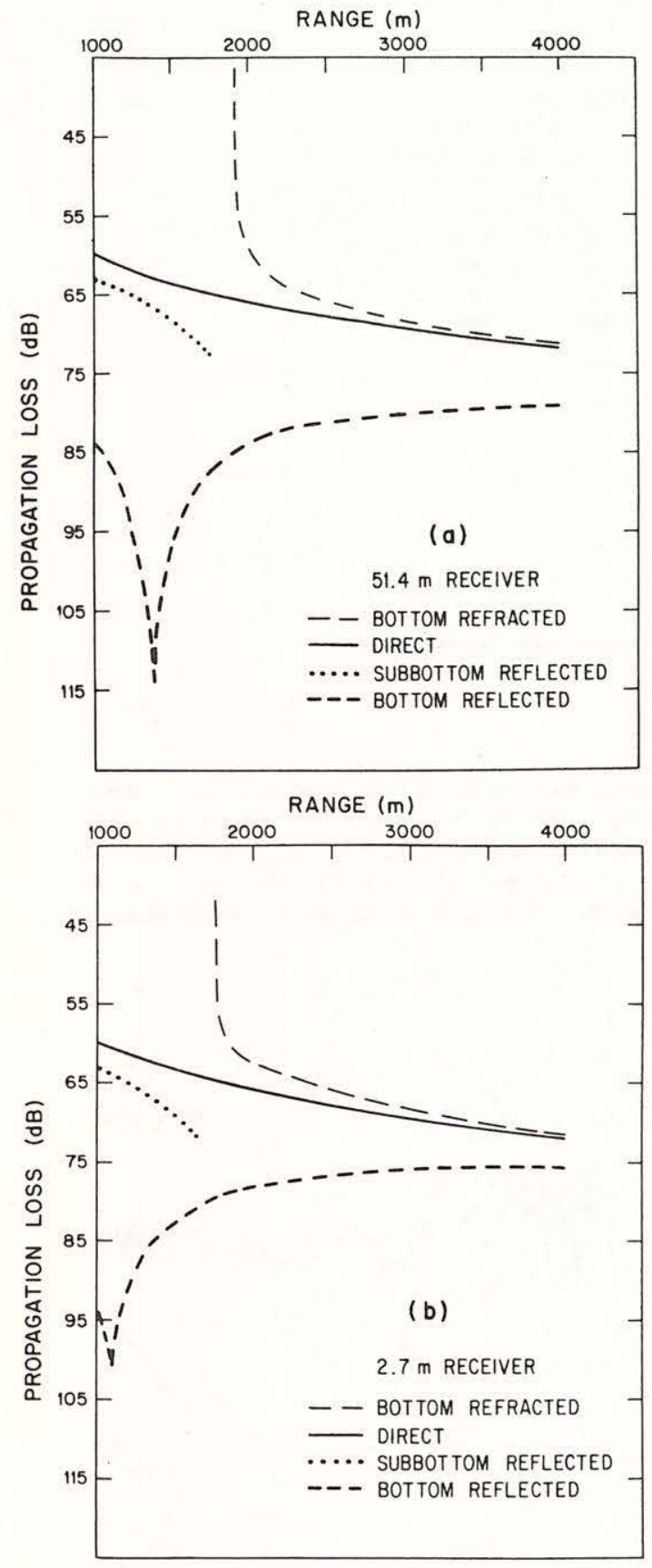

FIG. 10. Propagation loss for the direct and bottom-interacting ray paths for the (a) $51.4-\mathrm{m}$ and (b) $2.7-\mathrm{m}$ receivers using the geoacoustic model of Fig. 7 .

from the ones calculated in Fig. 11.

The sediment attenuation was determined by varying its value, with all other parameters held fixed, until the predicted and measured null depths agreed (c.f. Sec. IIA and the Appendix). A value of

$$
\alpha=8.686 \alpha^{\prime}=0.0015 \mathrm{~dB} / \mathrm{m} \text { at } 220 \mathrm{~Hz},
$$

was obtained using null 3 with both the ray model and the normal mode model described in the next section. This value is among the lowest values reported to date in the literature..$^{15-17}$ We note that the sediment at the experimental site is composed of sand and silt. ${ }^{11}$

\section{Comparison with a normal mode model}

The most comprehensive model used in our comparisons was Bartberger' ${ }^{14}$ normal mode program BOTMODE, which is related to his earlier work..$^{18}$ It is a full wave model which uses the same sound speed profiles as BOTRAY, thus yielding Airy function solutions to the depth-dependent Helmholtz equation. In BOTMODE, the normal modes are divided into two groups: (a) Water modes, whose equivalent rays have turning points in the water, and (b) sediment modes, whose equivalent rays penetrate into the bottom. The treatment of the water modes is an outgrowth of the approach used by Pedersen and Gordon ${ }^{19}$ for the related surface reflection problem. For a typical case, BOTMODE used approximately 600 water modes and 44 sediment modes. We obtained our best normal mode fit to the data, shown in Fig. 12, using the geoacoustic model in Fig. 7. The overall agreement between theory and experiment is excellent, with the only substantial deviations occurring at the longer ranges $(z 2700 \mathrm{~m})$. We shall reserve a discussion of this behavior for the next section. Finally we note that, in this case, normal mode theory is clearly superior to phase corrected ray theory only in predicting the amplitude in the vicinity of the caustic.

\section{Comparison with the parabolic equation method}

Perhaps the most interesting results were those obtained using the parabolic equation method (PEM). ${ }^{20}$ At first glance, one might expect this approach to be inappropriate because of our conditions of strong bottom interaction. On the other hand, the narrow band of initial angles $\left(<30^{\circ}\right)$ leaving the source in our case (c.f. Fig. 6) suggest that the paraxial approximation inherent in the PEM may be reasonably well satisfied. Furthermore, while the PEM in its standard form assumes a perfectly reflecting soft surface and absorbing bottom, we assume a totally reflecting subbottom and absorbing surface. This led us to the idea of using the profile shown in Fig. 13 as input to the PEM. Since the desired profile was that shown in Fig. 14, we simply input source/ receiver heights above the subbottom as source/receiver depths below the surface in Fig. 13. The results, shown in Fig. 15, are remarkable, since this version of the $\mathrm{PEM}^{21}$ contains neither density stratification nor attenuation. This indicates that at these low angles, the bottom interaction process may be modeled as a propagation process combined with the effect of a perfect soft subbottom reflector. These results are consistent with our ray interpretation which indicated that the primary role of the water-bottom interface is to serve as a "window" for the rays which enter the sediment and subsequently interact strongly with the gradient and subbottom.

The geoacoustic model obtained with the PEM also differs from that obtained with the ray and normal mode programs in the form of the sound-speed profile and the 
TABLE II. Experimental and ray theoretical null ranges and spacings.

\begin{tabular}{|c|c|c|c|c|c|c|c|c|}
\hline \multirow{3}{*}{$\begin{array}{l}\text { Null } \\
\text { no. }\end{array}$} & \multicolumn{4}{|c|}{ (a) $51.4-\mathrm{m}$ receiver } & \multicolumn{4}{|c|}{ (b) $2.7-\mathrm{m}$ receiver } \\
\hline & \multicolumn{2}{|c|}{ Null range $(\mathrm{m})$} & \multicolumn{2}{|c|}{ Null spacing (m) } & \multicolumn{2}{|c|}{ Null range $(\mathrm{m})$} & \multicolumn{2}{|c|}{ Null spacing $(\mathrm{m})$} \\
\hline & Theory & Experiment & Theory & Experiment & Theory & Experiment & Theory & Experiment \\
\hline 1 & 1070 & 1101 & & & 1130 & 1119 & & \\
\hline 2 & 1150 & 1155 & 80 & 54 & 1200 & 1239 & 70 & 120 \\
\hline 3 & 1200 & 1236 & 50 & 81 & 1290 & 1305 & 90 & 66 \\
\hline 4 & 1260 & 1281 & 60 & 45 & 1350 & 1386 & 60 & 81 \\
\hline 5 & 1350 & 1353 & 90 & 72 & 1430 & 1494 & 80 & 108 \\
\hline 6 & 1400 & 1431 & 50 & 78 & $\left\{\begin{array}{l}2260^{\mathrm{a}} \\
1760^{\mathrm{b}}\end{array}\right.$ & $1971\} \mathrm{R}$ & efracted & \\
\hline 7 & 1480 & 1494 & 80 & 63 & & & & \\
\hline 8 & 1560 & 1626 & 80 & 132 & & & & \\
\hline 9 & 1640 & 1710 & 80 & 84 & & & & \\
\hline 10 & 1740 & 1830 & 100 & 120 & & & & \\
\hline 11 & $\left\{\begin{array}{l}2000^{a} \\
2100^{b}\end{array}\right.$ & 2391 & & & & & & \\
\hline 12 & $\left\{\begin{array}{l}2500^{\mathrm{a}} \\
2740^{\mathrm{b}}\end{array}\right.$ & 3000 & $\begin{array}{l}500^{\mathrm{a}} \\
640^{\mathrm{b}}\end{array}$ & $609\}^{\mathrm{R}}$ & racted & & & \\
\hline
\end{tabular}

a Without $90^{\circ}$ phase shift due to caustic.

${ }^{\mathrm{b}}$ With $90^{\circ}$ phase shift due to caustic.

layer thickness. Linear gradients gave the best overall results with the PEM at both receivers. In fact, we believe that the linear gradient in the sediment was the source of our improved agreement, relative to the results using BOTRAY and BOTMODE, in the long-range falloff of the field at the $2.7-\mathrm{m}$ receiver. Other measurement $\mathrm{s}^{22}$ indicate the form of the sediment soundspeed profile to be $c^{2}$ linear; $c$ linear is closer to this form than $1 / c^{2}$ linear, thus yielding the improved results. On the other hand, we found that while actually

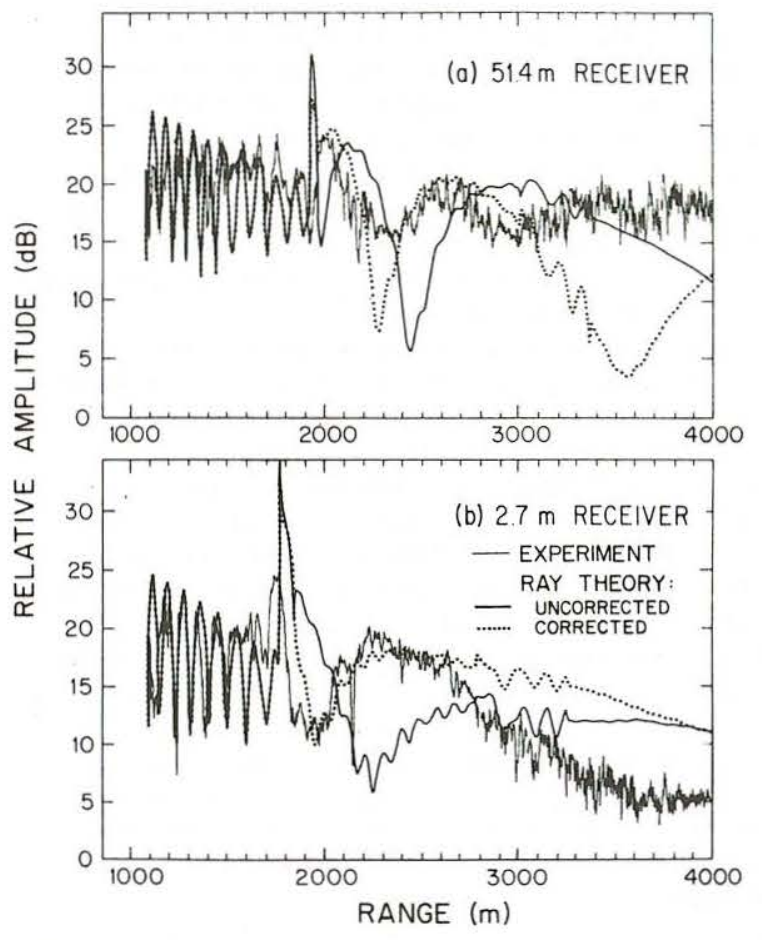

FIG. 11. Comparison of experiment and ray theory with and without the caustic phase correction using the geoacoustic model of Fig. 7 for the (a) 51.4-m and (b) 2.7-m receivers.

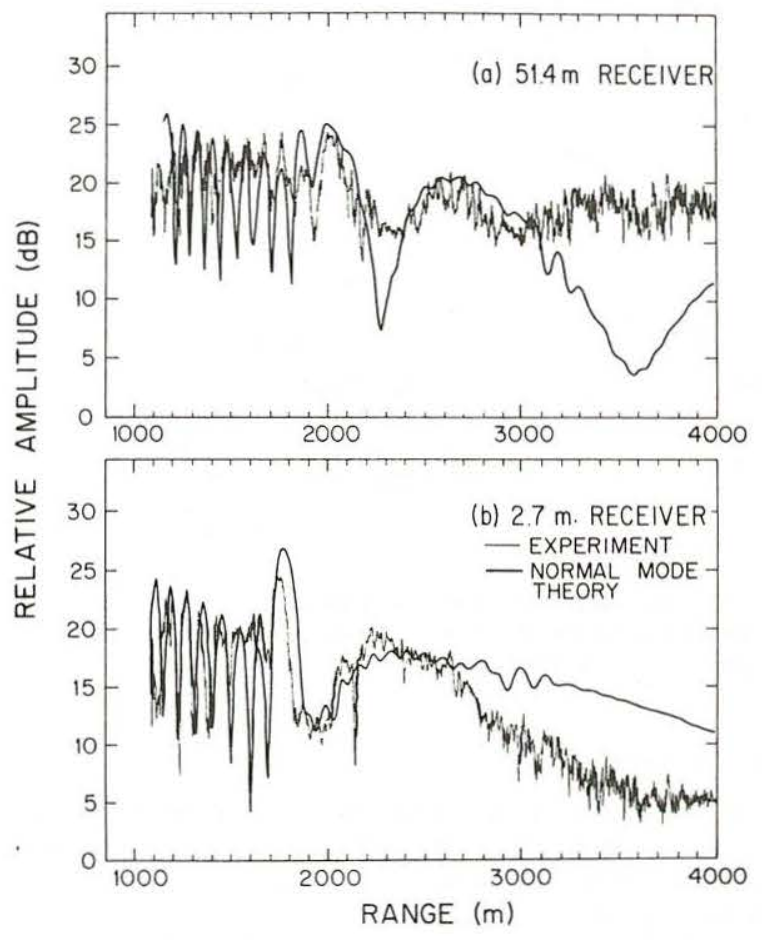

FIG. 12. Comparison of experiment and normal mode theory 1sing the geoacoustic model of $\mathrm{Fig}$. 7 for the (a) $51.4-\mathrm{m}$ and (b) 2.7-m receivers. 


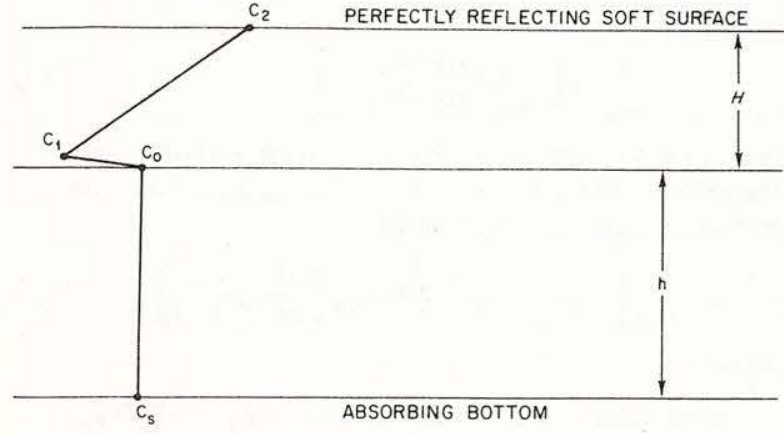

FIG. 13. Form of the sound-speed profile input to the parabolic equation program.

using a $c^{2}$ linear profile in the PEM slightly improved the results at the $2.7-\mathrm{m}$ receiver, it made the results at the 51.4-m receiver slightly worse. In any case, we can conclude that the field is very sensitive to the form of the profile at extreme grazing incidence.

We expect the normal mode program to yield a more reliable estimate of layer thickness than the PEM because of the phase errors introduced in the PEM at steep angles by the paraxial approximation..$^{20,23}$ The layer thickness strongly influences the nature of the interference pattern in region $\mathrm{A}$ of the data. If there is a phase error associated with the subbottom-reflected path, it will appear as an error in the inferred layer thickness. We believe this to be the source of the discrepancy even though our PEM program included the phase velocity correction discussed in Ref. 23 because our steepest angles fall outside the nominal $20^{\circ}$ range for which the PEM is considered most reliable. Another possible source of error is the approximation of a soft reflector at the sediment-subbottom interface for which the phase $\phi_{23}=-180^{\circ}$, when in fact the rangeaveraged phase is approximately $\left\langle\phi_{23}\right\rangle=-100^{\circ}$. However, because of the insensitivity of the amplitude to the subbottom properties discussed earlier (c.f. Sec. IIB), we do not believe this to be a major source of error.

\section{CONCLUSIONS}

We have presented the results of a deep-ocean bottom interaction experiment for small grazing angles at 220 $\mathrm{Hz}$ in which the effects of both bottom refraction and subbottom reflection were observed. The measured amplitude shows a strong spatial interference pattern which is composed of the direct and bottom interacting arrivals. It was shown that for small source-receiver separations, the bottom return is dominated by a strong subbottom reflection. With increasing separation this arrival evolves into a refracted arrival due to the presence of a positive sound-speed gradient in the overlying sediment. Because of the gradient a caustic is formed, and corresponding high intensity regions are observed in the data at the expected ranges. Values of sediment layer thickness, sound-speed gradient, and sound-speed drop at the water-bottom interface were obtained from best fits to the data using ray theory, normal mode theory, and the parabolic equation method. These values are consistent with those obtained in nearby locations by other workers. The success of the parabolic equation method indicated that at small grazing angles the bottom interaction process could be modeled as a propagation process combined with the effect of a perfect, soft subbottom reflector. A value of sediment attenuation, $0.0015 \mathrm{~dB} / \mathrm{m}$ at $220 \mathrm{~Hz}$, was also inferred from the data and was found to be among the lowest values reported to date in the literature.

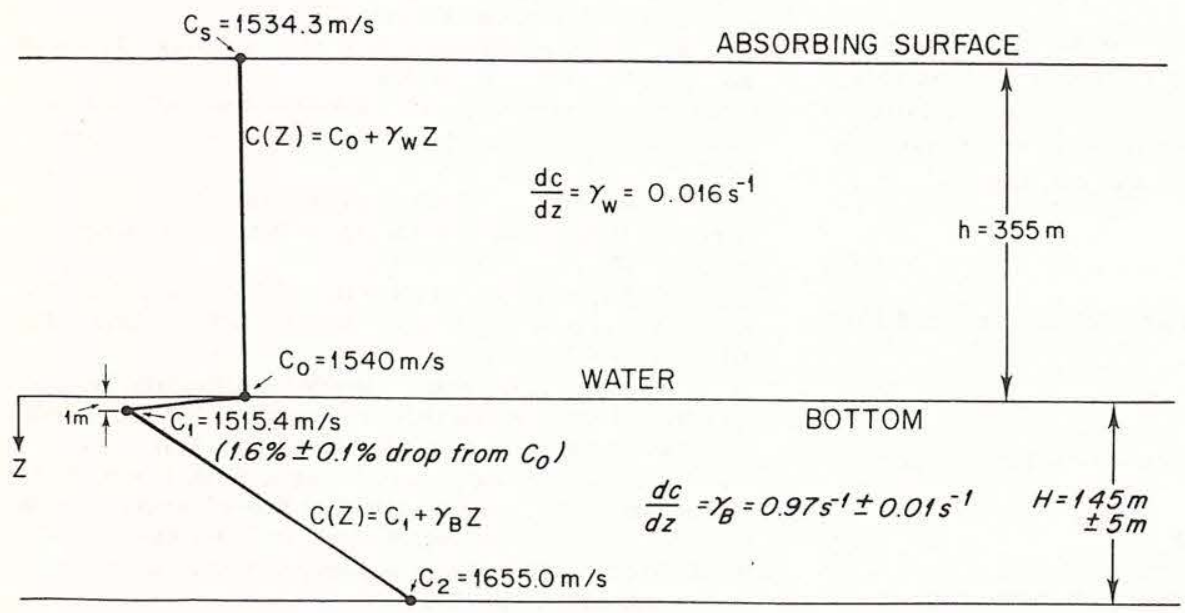

FIG. 14. Geoacoustic model used with the parabolic equation method.

PERFECTLY REFLECTING SOFT SUBBOTTOM 

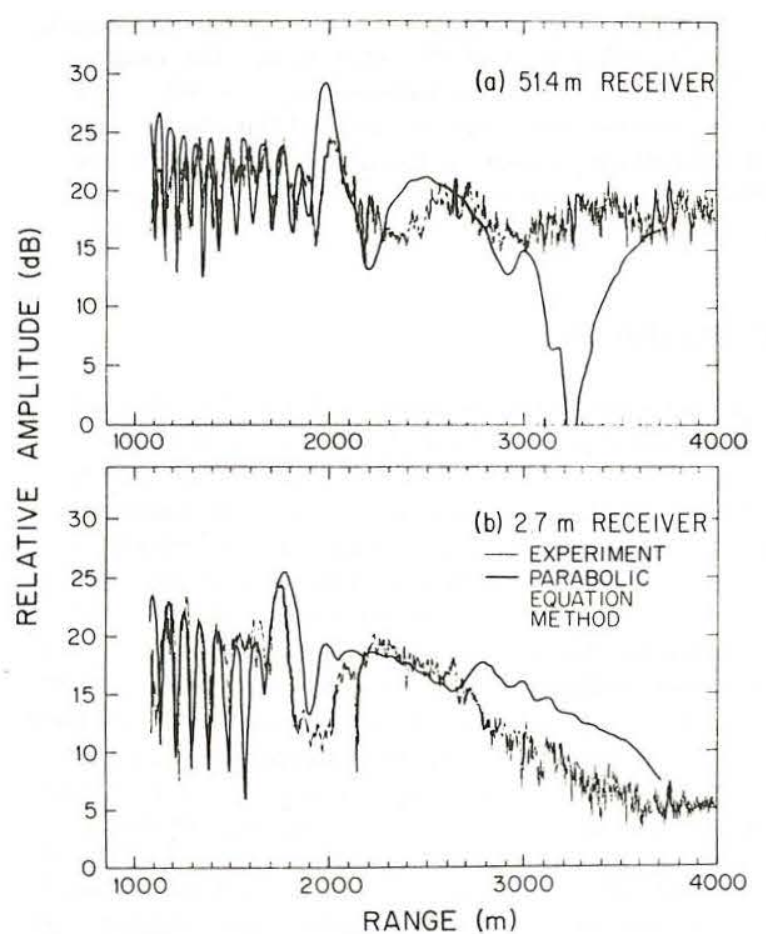

FIG. 15. Comparison of experiment and the parabolic equation method using the geoacoustic model of Fig. 14 for the (a) $51.4-\mathrm{m}$ and (b) $2.7-\mathrm{m}$ receivers.

\section{ACKNOWLEDGMENTS}

The authors are grateful to Charles L. Bartberger for providing the ray and normal mode theory results. Thanks are due Robert C. Spindel and Paul R. Boutin for their assistance in carrying out the experiment. The authors thank Hiroshi Kawahara for performing the reflection coefficient computations. This work was supported by Contract N00014-77-C-0196 administered through NORDA. This paper is WHOI Contribution No. 4584 .

\section{APPENDIX: A METHOD FOR MEASURING SEDIMENT ATTENUATION}

It was shown in Sec. ILA that the dominant paths giving rise to the interference pattern in region $\mathrm{A}$ of the data are the direct path and a bottom path which is totally reflected at the subbottom. The paths are in phase at a peak in the data and have amplitude [c.f. Eqs. (4), (6), and (10)]

$$
|p|_{\text {Deak }}=A_{D}+A_{S B} e^{-\alpha^{\prime} L S B} .
$$

At the adjacent null, the paths are out of phase and have amplitude

$$
|p|_{\text {aull }}=A_{D}-A_{\mathrm{SB}} e^{-\alpha^{\prime} L_{\mathrm{SB}}} .
$$

We can measure the decibel peak -to-null difference in amplitude $D$ from the data:

$$
D \equiv 20\left(\log _{10}|p|_{\text {Deak }}-\log _{10}|p|_{\text {null }}\right) .
$$

We can then solve for the sediment attenuation $\alpha^{\prime}$ in terms of $D$, the spreading losses $A_{D}$ and $A_{\mathrm{SB}}$, and the sediment path length $L_{\mathrm{SB}}$;

$$
\alpha^{\prime}=-\frac{1}{L_{\mathrm{SB}}} \ln \left[\frac{A_{D}}{A_{\mathrm{SB}}}\left(\frac{10^{D / 20}-1}{10^{D / 20}+1}\right)\right] .
$$

We can also express the result in terms of $\mathrm{dB} / \mathrm{m}$ and the $\mathrm{dB}$ spreading losses $P L_{D}$ and $P L_{\mathrm{SB}}$ along the direct and subbottom reflected paths:

$$
\alpha=\frac{1}{L_{\mathrm{SB}}}\left[P L_{D}-P L_{\mathrm{SB}}-20 \log _{10}\left(\frac{10^{D / 20}-1}{10^{D / 20}+1}\right)\right],
$$

where

$$
\alpha=8.686 \alpha^{\prime}, \quad P L_{D}=-20 \log _{10} A_{D}, \quad P L_{\mathrm{SB}}=-20 \log _{10} A_{\mathrm{SB}} .
$$

We applied this method to null 3 and the adjacent peaks in our $2.7-\mathrm{m}$ receiver data. The deeper receiver was used because of its superior signal-to-noise ratio. The La Spezia ray program ${ }^{13}$ was used to compute the ray parameters. For null 3 and the preceding peak, we found

$$
D_{-}=12.5 \mathrm{~dB}, \quad \alpha_{-}=0.0011 \mathrm{~dB} / \mathrm{m} .
$$

For null 3 and the following peak, we found

$$
D_{+}=10.6 \mathrm{~dB}, \alpha_{+}=0.0022 \mathrm{~dB} / \mathrm{m} \text {. }
$$

The average of these two results yields

$$
\langle\alpha\rangle=0.0017 \mathrm{~dB} / \mathrm{m},
$$

a value which is in close agreement with the trial-anderror result obtained in Sec. IIB.

${ }^{1}$ R. E. Christensen, J. A. Frank, and W. H. Geddes, "LowFrequency Propagation Via Shallow Refracted Paths through Deep-Ocean Unconsolidated Sediments," J. Acoust. Soc. Am. 57, 1421-1426 (1975).

${ }^{2}$ R. L. Dicus, "Preliminary Investigations of the Ocean Bottom Impulse Response at Low Frequencies," Technical Note No. 6130-4-76 (Naval Oceanographic Office, Washington, DC, May 1976) (unpublished).

${ }^{3}$ A. Silbiger, "Phase Shift at Caustics and Turning Points," J. Acoust. Soc. Am. 44, 653-654 (1968).

${ }^{4}$ I. Tolstoy, "Phase Changes and Pulse Deformation in Acoustics," J. Acoust. Soc. Am. 44, 675-683 (1968).

${ }^{5}$ D. A. Sachs and A. Silbiger, "Focusing and Refraction of Harmonic Sound and Transient Pulses in Stratified Media," J. Acoust. Soc. Am. 49, 824-840 (1971).

${ }^{6}$ D. A. Sachs, "Sound Propagation in Shadow Zones," J. Acoust. Soc. Am. 51, 1091-1097 (1972).

${ }^{7} \mathrm{~J}$. S. Hanna, "Short-Range Transmission Loss and the Evidence for Bottom-Refracted Energy," J. Acoust. Soc. Am. 53, 1686-1690 (1973).

${ }^{8}$ M. V. Brown and J. H. Ricard, "Interference Pattern Observed in Reflections from the Ocean Bottom," J. Acoust. Soc. Am. 37, 1033-1036 (1965).

${ }^{9}$ R. C. Spindel, R. P. Porter, and D. C. Webb, "A Mobile Coherent Low-Frequency Acoustic Range," IEEE J. Ocean. Eng. OE-2, 331-337 (1977).

${ }^{10}$ R. E. Houtz and J. I. Ewing, "Detailed Sedimentary Velocities from Seismic Refraction Profiles in the Western North Atlantic," J. Geophys. Res. 68, 5233-5358 (1963).

${ }^{11}$ K. O. Emery, E. Uchupi, J. D. Phillips, C. O. Bowin, E. T. Bunce, and S. T. Knott, "Continental Rise off Eastern North America," Am. Assoc. Petrol. Geol. Bull. 54, 44-108 (1970).

${ }^{12}$ L. M. Brekhovskikh, Waves in Layered Media (Academic, New York, 1960), pp. 15-22.

${ }^{13}$ M. Thompson and J. Padley, NATO SACLANT ASW Research 
Centre, La Spezia, Italy (private communication).

${ }^{14}$ C. Bartberger, Naval Air Development Center, Warminster, PA (private communication).

${ }^{15}$ E. L. Hamilton, "Sound Attenuation as a Function of Depth in the Sea Floor," J. Acoust. Soc. Am. 59, 528-535 (1976).

${ }^{16}$ R. S. Anderson and A. Blackman, "Attenuation of Low Frequency Sound Waves in Sediments," J. Acoust. Soc. Am. 44, 786-790 (1971).

${ }^{17}$ S. K. Mitchell and K. C. Focke, "New Measurements of Compressional Wave Attenuation in Deep Ocean Sediments," J. Acoust. Soc. Am. 67, 1582-1589 (1980).

${ }^{18} \mathrm{C}$. Bartberger, "Normal Mode Solutions and Computer Programs for Underwater Sound Propagation," Part I-TwoLayer and Three-Layer Programs, Naval Air Development Center, Report No. NADC-72001-AE (4 April 1973) (unpublished).

${ }^{19}$ M. A. Pedersen and D. F. Gordon, "Normal-Mode and Ray
Theory Applied to Underwater Acoustic Conditions of Extreme Downward Refraction," J. Acoust. Soc. Am. 51, 323368 (1972).

${ }^{20}$ F. D. Tappert, "The Parabolic Approximation Method," in Wave Propagation and Underwater Acoustics, edited by J. B. Keller and J. S. Papadakis (Springer, Berlin, 1977), Lecture Notes in Physics, Vol. 70.

${ }^{21}$ Computer program obtained from Acoustic Environmental Support Detachment, Office of Naval Research, Arlington, VA.

${ }^{22}$ E. L. Hamilton, "Sound Velocity Gradients in Marine Sediments," J. Acoust. Soc. Am. 65, 909-922 (1979).

${ }^{23}$ H. K. Brock, R. N. Buchal, and C. W. Spofford, "Modifying the Sound-Speed Profile to Improve the Accuracy of the Parabolic-Equation Technique," J. Acoust. Soc. Am. 62, 543-552 (1977). 


\section{MANDATORY DISTRIBUTION LIST}

FOR UNCLASSIFIED TECHNICAL REPORTS, REPRINTS, AND FINAL REPORTS PUBLISHED BY OCEANOGRAPHIC CONTRACTORS

OF THE OCEAN SCIENCE AND TECHNOLOGY DIVISION

OF THE OFFICE OF NAVAL RESEARCH

(REVISED NOVEMBER 1978)

1 Deputy Under Secretary of Defense

(Research and Advanced Technology)

Military Assistant for Environmental Science

Room 30129

Washington, D.C. 20301

Office of Naval Research

800 North Quincy Street

Arlington, VA 22217

3 ATTN: Code 483

1 ATTN: Code 460

2 ATTN: 102B

1 COR J. C. Harlett, (USN)

ONR Representative

Woods Hole Oceanographic Inst.

Woods Hole, MA 02543

Commanding Officer

Naval Research Laboratory

Washington, D.C. 20375

6
12 Defense Documentation Center Cameron Station

Alexandria, VA 22314

ATTN: DCA

Commander

Naval Oceanographic Office NSTL Station

Bay St. Louis, MS 39522

1 ATTN: Code 8100

ATTN: Code 6000

ATTN: Code 3300

1 NODC/NOAA

Code 0781

Wiscons in Avenue, N.W.

Washington, D.C. 20235 


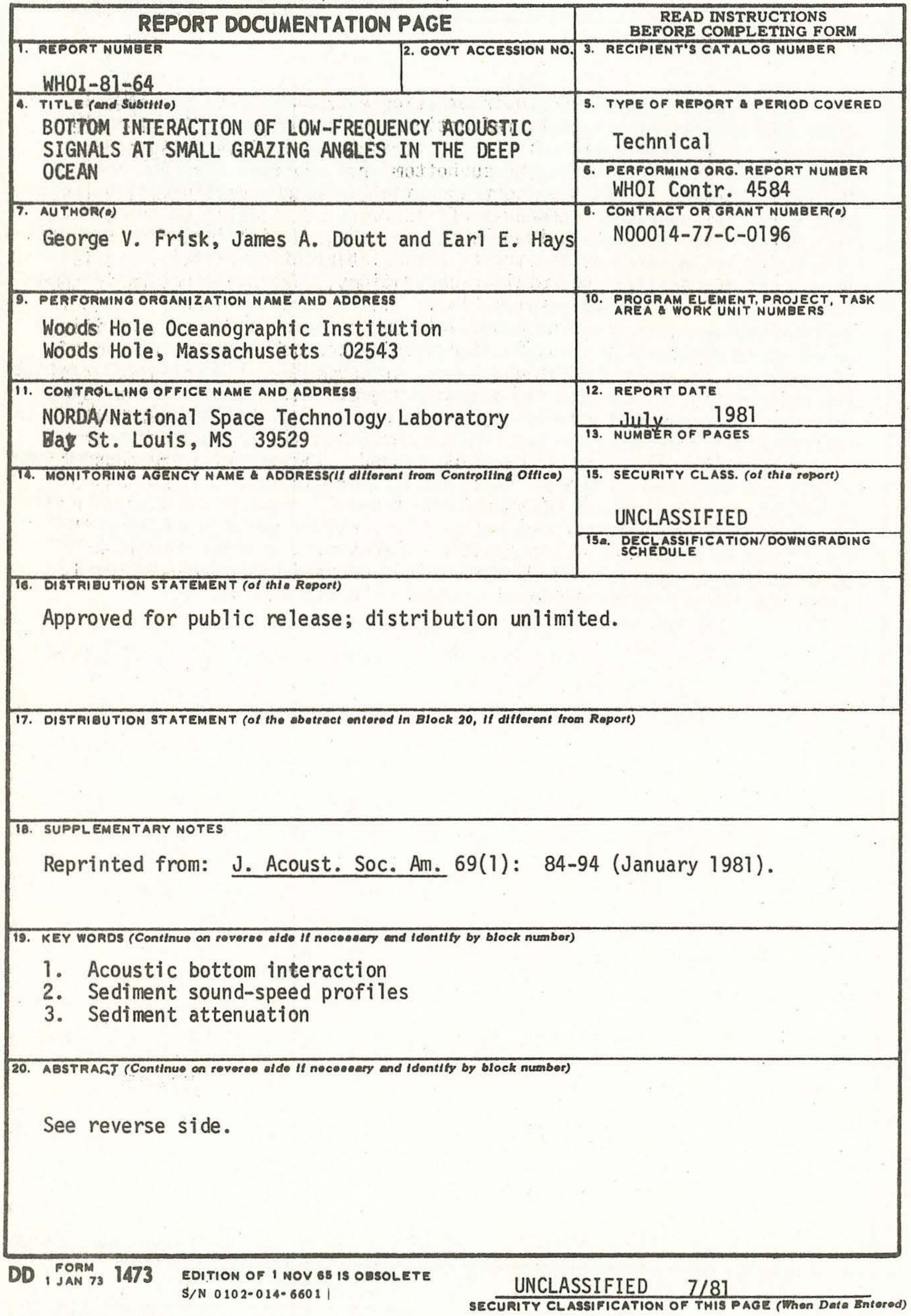


20.

The results of a deep-ocean interaction experiment are presented in which the effects of both bottom refraction and subbottom reflection were observed. Data were obtained in the Hatteras Abyssal Plain using a deep towed $220-\mathrm{Hz}$ pulsed $\mathrm{CW}$ source and two receivers anchored near the bottom. For ranges between 1 and $6 \mathrm{~km}$, corresponding to bottom grazing angles less than $13^{\circ}$, the quadrature components of the received signals were recorded digitally. The observed amplitude shows a strong spatial interference pattern which is composed of the direct bottom interacting arrivals. It is shown that for small source-receiver separations, the bottom return is dominated by a strong subbottom reflection. With increasing separation, this arrival evolves into a refracted arrival due to the presence of a positive sound-speed gradient in the sediment overlying the subbottom. Because of the gradient, a caustic is formed, and corresponding high intensity regions are observed in the data at the expected ranges. Values of sediment layer thickness, sound-speed gradient, and sound speed drop at the water-bottom interface are obtained from best fits to the data using ray theory, normal mode theory, and the parabolic equation method. These values are consistent with those obtained in nearby locations by other workers. The success of the parabolic equation method indicates that at small grazing angles, the bottom interaction process may be modeled as a propagation process combined with the effect of a perfect, soft subbottom reflector. A value of sediment attenuation, $0.0015 \mathrm{~dB} / \mathrm{m}$ at $220 \mathrm{~Hz}$, is also inferred from the data and is among the lowest values reported to date in the literature. 


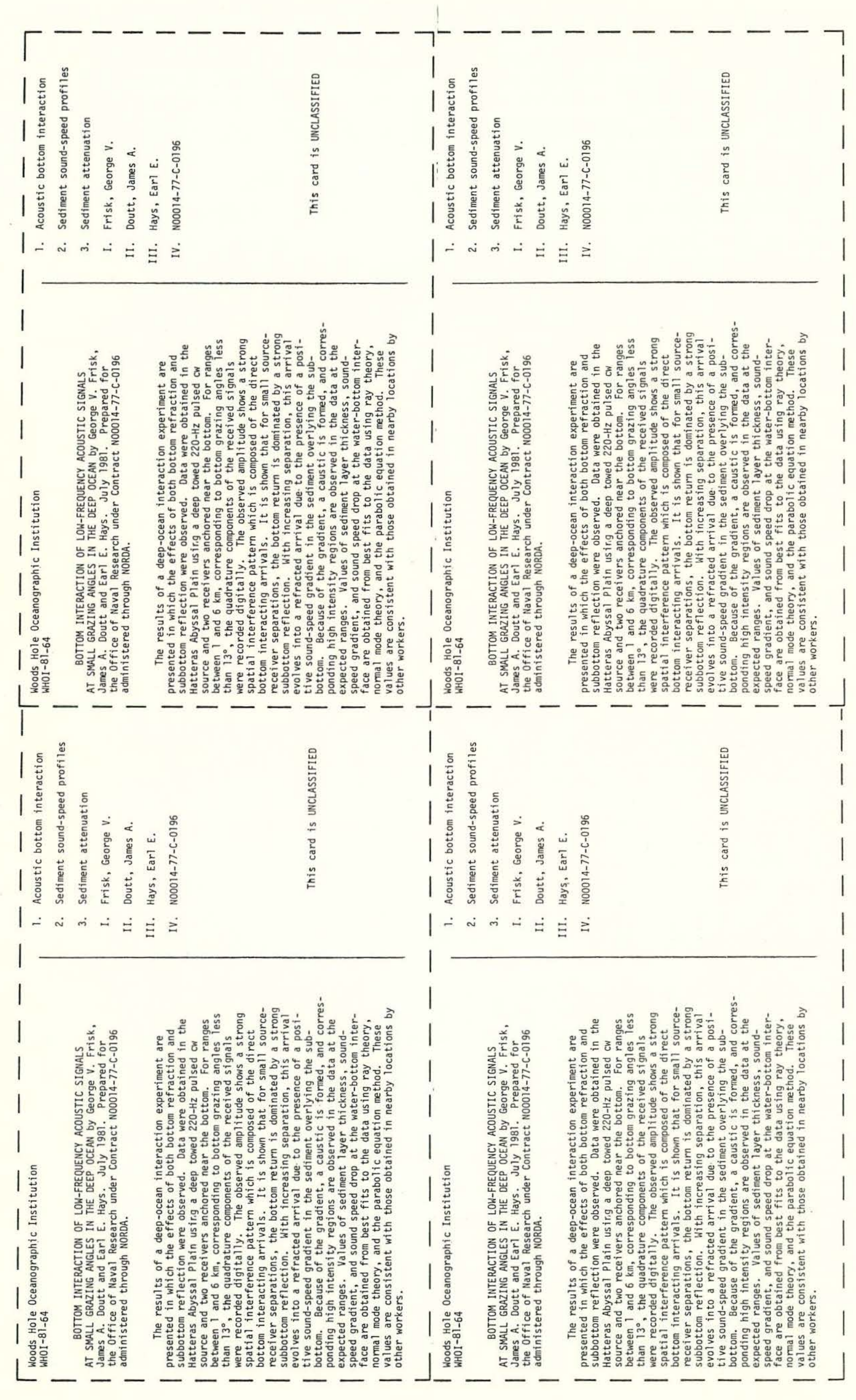

